\title{
O Imaginário Educacional na Perspetiva de Gilbert Durand
}

\author{
Alberto Filipe Araújo' \\ Fernando José Azevedo' \\ 'Universidade do Minho (UM), Braga - Portugal
}

RESUMO - O Imaginário Educacional na Perspetiva de Gilbert Durand. Este artigo parte da obra de Gilbert Durand e opta preferencialmente pela noção heurística da mitanálise, ainda que num sentido mais lato, em detrimento da noção de mitocrítica mais vocacionada para a crítica literária e poética. O ponto de vista defendido é que a bacia semântica na qual a mitanálise, concebida para con-textos mais ideologizados, opera é a do imaginário educacional com o seu conceito de ideologema. É, portanto, neste pano de fundo que se desenrolará a discussão, na nossa última parte, do interesse e da respectiva importância da mitanálise no quadro de uma hermenêutica educacional que, por sua vez, não deixará de ter implicações numa Filosofia da Educação.

Palavras-chave: Mitanálise. Imaginário Educacional. Hermenêutica Educacional. Ideologema.

ABSTRACT - The Educational Imaginary in Gilbert Durand's Perspective. This article stems from the work of Gilbert Durand and preferentially opts the heuristic notion of myth-analysis, although in a much broader sense, to the detriment of the notion of myth-criticism, more orientated towards literary and poetic criticism. The advocated point of view here is that the semantic basin in which the myth-analysis operates, conceived for more ideologized contexts, is that of the educational imaginary with its concept of ideologeme. It is, therefore, in this context that the discussion will take place, in our last section,envisaging the importance and interest of Myth-analysis and its implications in an educational hermeneutics panorama, which in turn will not fail to have implications in the Philosophy of Education.

Keywords: Myth-Analysis. Educational Imaginary. Educational Hermeneutics. Ideologeme.

Educação \& Realidade, Porto Alegre, v. 43, n. 1, p. 73-95, jan./mar. 2018. 73 http://dx.doi.org/10.1590/2175-623663498 
O Imaginário Educacional na Perspetiva de Gilbert Durand

\section{Introdução}

O presente estudo tem como ponto de partida o estudo de Alberto Filipe Araújo e Armando Malheiro da Silva (2003), no qual os autores fazem uma leitura da mitanálise durandiana numa perspectiva mais da hermenêutica simbólica do que da sociologia de profundidades propriamente dita. Nesse estudo, os autores advogam que a mitocrítica, com os seus conceitos operatórios, destinada à captação dos mitos nos textos literários (Durand, 1994; 1996; 2000), não se adapta à especificidade de textos fortemente ideologizados e pobres de expressividade mítica, como é o caso dos textos educacionais e pedagógicos.

O nosso ponto de vista é que a mitocrítica está vocacionada para captar e tratar os mitos e suas figuras patentes nos textos literários e poéticos, enquanto a mitanálise durandiana está orientada para detectar os mitos diretores que animam as sociedades ao longo do seu tempo e do seu espaço: se é verdade que a mitanálise visa a uma arqué é para melhor se sentir reconfortada nas novas significações socioculturais e míticas que visa igualmente instaurar (telos). Por outras palavras, a mitanálise carece de imergir numa espécie de arcaísmo das profundezas de determinada bacia semântica para, em seguida, emergir como "[...] a via possível de uma descoberta, de uma prospecção, de uma profecia de nós mesmos" (Ricoeur, 1988, p. 176), doadora de significações transmutadoras de ídolos em deuses no sentido que Neil Postman (2002) lhes confere, isto é, como grandes narrativas ${ }^{1}$. Para que tal aconteça, todo um trabalho genealógico, diríamos mesmo arqueológico, se impõe à luz da tradição mítica ocidental, simbólica e metafórica. Se a coisa educativa não pode escapar aos símbolos da cultura que a originou, leia-se com-texto ideo-sociocultura e histórico, também não deixa de ser verdade que imagens constantes invariáveis (aquilo que Jung denomina de imagens arquetípicas) estruturantes do imaginário humano não possam também apalavrá-la de modo pregnante. É, portanto, neste quadro epistemológico que a mitanálise tem o seu lugar.

Assim, ante ao já exposto, procuraremos explicitar de que modo a mitanálise poderá, enquanto via mitodológica, dar conta dos mitos e do seu rasto, dos símbolos, das suas metáforas e alegorias mediados especialmente pela figura do ideologema que se afirma como uma das noções heurísticas do imaginário educacional. Com a utilização deste conceito, já estamos a dar um sentido mais hermenêutico e menos sociológico à mitanálise durandiana. Por outras palavras, empregamos este conceito hermenêutico no seu sentido mais amplo e enquanto prolongamento da própria mitocrítica como, aliás, o sublinharemos ao longo do texto.

Com o objetivo de traçarmos um programa simultaneamente metodológico e mitodológico, organizaremos o nosso estudo em três partes: a primeira ocupar-se-á de definir o imaginário educacional e o conceito de ideologema; na segunda exporemos a teoria de Durand sobre a mitanálise com os seus conceitos operatórios da tópica sociocultural e da bacia semântica, e na quarta parte, que é a última e que funcionará 
a modos de conclusão, falaremos do interesse da mitanálise para uma hermenêutica dos textos educacionais.

\title{
Para uma Definição de Imaginário Educacional e do Conceito de Ideologema
}

O imaginário educacional, enquanto imaginário sociocultural está pouco exposto aos mitos, símbolos e mais receptivo às figuras semânticas da alegoria e da metáfora. É assim, que aparece o conceito de ideologema que estabelece a ponte entre o imaginário sociocultural e o imaginário mítico (no fundo trata-se de um imaginário bidimensional) que articula o semantismo cultural (alegorias e metáforas) com o pré-semantismo próprio dos símbolos primários (cósmicos, oníricos e poéticos) e dos símbolos mais complexos (mitos).

\section{Do Imaginário Educacional}

O imaginário educacional - como imaginário híbrido - é tanto devedor do imaginário social (Ricoeur, 1986a) como do imaginário mítico (Durand, 1996). Ele é uma espécie de entre dois porque se, por um lado, a educação não se pode furtar, como o notaram Daniel Hameline (1986), Nanine Charbonnel (1991a, 1991b, 1993) e Graham Low (2010, p. 212-231), ao poder das metáforas, por outro lado, os textos, os seus discursos e os seus ditos não podem deixar de ser portadores de núcleos pregnantes de ideologia. Por outras palavras, o imaginário educacional situa-se entre o imaginário social (ideologia-utopia) e o imaginário mítico dotado este de uma potencial riqueza simbólica e metafórica. Neste contexto, o imaginário educacional pode ser denominado de bidimensional porque é simultaneamente sociocultural (níveis racional e actancial) e arquetipal (nível fundador: o mundo do inconsciente coletivo com o seu par de arquétipos-imagens arquetípicas na terminologia de Jung): sendo esta simultaneidade configurada pelo conceito durandiano de tópica sociocultural (Durand, 1994; 2000). Por outras palavras, as dimensões do imaginário social e cultural (Paul Ricoeur, Gilbert Durand) e do imaginário arquetipal (Durand, Jung, James Hillman) são inseparáveis, tal como o bem demonstrou Durand na sua tópica sociocultural. Daí pensarmos que é a noção de imaginário bidimensional que deve ser privilegiada:

\begin{abstract}
A metalinguagem primordial emerge na língua natural do grupo social. O inconsciente coletivo faz-se cultural; as cidades, os monumentos, as construções da sociedade vêm captar e identificar a pulsão dos arquétipos na memória do grupo. A cidade concreta vem modelar o desejo da 'cidade ideal', porque uma utopia nunca está isolada do seu nicho sócio-histórico. Os verbos e os epítetos que caracterizam a generalidade do inconsciente específico substancializam-se (Durand, 2000, p. 142).
\end{abstract}

Trata-se de um tipo de imaginário empobrecido porque é uma especificação daquilo que designamos de imaginário bidimensional 
que articula, por sua vez, o registo sociocultural (ideologia, ideologe$m a$, utopia, metáfora, alegoria) e o mítico (narrativas simbólicas com os seus símbolos fortes). Deste modo, o hermeneuta vê-se impelido a utilizar, entre outras escolhas metodológicas possíveis, a Mitanálise (sem, contudo esquecer a Mitocrítica), tal como ela foi concebida por Durand (1994; 1996; 2000), Vierne (1993) e Araújo e Silva (2003), para interpretar mítico-simbolicamente os textos e as práticas discursivas educacionais.

Neste sentido, mesmo constatando que a presença massiva de metáforas nos textos e discursos educativos é uma constante e se elas, como diz Ricoeur (1987, p. 57-81), nos abrem a janela ao simbólico, o hermeneuta do imaginário educacional tem que afinar, ou melhor, ajustar, a proposta mitanalítica durandiana com o objetivo de tornar mais audíveis e mais inteligíveis as figuras que habitam o imaginário educacional. Mesmo sabendo que esta inteligibilidade não é simplesmente dada, pois ela é sempre mediada pelas ideias pedagógicas e pelos “[...] ditos educativos", como Daniel Hameline (1994, p. 149-164) nos explicou, tal não significa que não haja possibilidades de ultrapassar os obstáculos que a interpretação simbólica sempre ergue ao longo do caminho do hermeneuta. Lembre-se, a título de exemplo, que um dos obstáculos maiores com o qual o hermeneuta se confronta é o da necessidade de provar o levantamento dos traços míticos nos interstícios dos textos analisados ou mesmo das práticas discursivas observadas. Por isso, é que dizemos que o imaginário educacional, estando muito próximo do imaginário ideológico, é ingrato do ponto de vista simbólico e mítico. A razão desta afirmação reside quer na sua falta de receptividade, quer na sua pouca plasticidade à atitude epistemológica da hermenêutica simbólica, obrigando por isso a que o intérprete mantenha uma atenção acrescida à fluência metafórica dos textos em análise, pois é ela que fornece um índice das figuras do imaginário.

\section{A Noção de Ideologema}

Quando se trata do imaginário educacional há uma noção, a de ideologema ${ }^{2}$, que aparece bem colocada para nos ajudar a melhor compreender a articulação do social e do mítico no interior do imaginário educacional. O imaginário educacional, pela sua natureza ideológica, utópica, metafórica e alegorizante, situa-se prevalentemente do lado do imaginário social (Ricoeur, 1986b), ainda que de acordo com a tópica sociocultural (Durand, 1994; 1996) ele não seja de todo imune à influência do imaginário mítico mesmo que se trate de uma influência rarefeita do ponto de vista de uma semântica profunda. A sua linguagem "natural é alegórica” (Reboul, 1991, p. 9) e metafórica ${ }^{3}$. Porém, tal não impede que do lado das metáforas não possam surgir boas surpresas, pois o mítico, e o simbólico que o acompanha, bem pode emergir ou fazer o seu aparecimento através dos fios metafóricos ${ }^{4}$. Neste contexto, não é de admirar que se evoque, normalmente sob a sua forma alegórica, os mitos de Prometeu, de Pigmalião, de Frankenstein, de Hermes, de Fausto e de Orfeu, só para falar dos principais. Cabendo em seguida

76 Educação \& Realidade, Porto Alegre, v. 43, n. 1, p. 73-95, jan./mar. 2018. 
aos estudiosos do imaginário fazerem uma hermenêutica adequada a fim de separarem a mensagem mítica da alegórica. No tocante aos seus domínios privilegiados, eles são, na nossa perspectiva, os seguintes: as utopias educacionais (presentes nas obras de Tomás Moro, Tomás Campanela, Francis Bacon, François Rabelais, etc.), os romances de formação (Bildungsroman), cujos autores bem podiam ser, para além de outros, J. W. Goethe, F. Hölderlin, Jean Paul Richter, Novalis e as Ideias Educativas (educabilidade, felicidade, utopia, progresso, perfectibilidade, natureza, cultura, homem novo, formação, conversão, etc.) com os seus autores integrados na vasta galeria da História da Educação e da Pedagogia: Rabelais, Montaigne, Rousseau, Maria Montessori, Célestin Freinet, Edouard Claparède, John Dewey e tantos outros.

Neste contexto, a noção de ideologema aparece como um conceito operativo auxiliar, para empregar aqui uma expressão querida a Gilbert Durand (1994, p. 56), do "miticiano", que foi forjado na base heurística do conceito durandiano de mitologema (tema mítico), da noção durandiana de "trajecto antropológico" (Durand, 1984b, p. 38) ${ }^{5}$, e na constatação de Jung que vê nos substantivos simbólicos, que são os arquétipos (designados de imagens primordiais em Tipos Psicológicos-Jung, 1991), “[...] o estado preliminar, a zona matricial da ideia” (Jung, 1991, p. 435). Gilbert Durand (1984b, p. 62-63) retomou esta observação capital para nos dizer o seguinte:

Longe de recalcar a imagem, a ideia representa o compromisso pragmático do arquétipo imaginário num dado contexto histórico e epistemológico. [...] Aquilo que seria, portanto dado 'ante rem' na ideia seria o seu molde afetivo-representativo, o seu motivo arquetipal; é aquilo que explica igualmente que os racionalismos e as démarches pragmáticas das ciências nunca se desembaracem completamente do halo imaginário, e que todo o racionalismo, todo o sistema racional traga em si os seus próprios fantasmas.

Podemos definir o ideologema como um complexo significante que articula e mobiliza, ao nível actancial (eu social da tópica), o sentido figurado (semantismo simbólico e afetivo-emocional) com as ideias-força veiculadas pelas ideologias (orientações mais conceptualizadas, mais abstratas e rarefeitas) e presentes em dado contexto histórico sociocultural. É, portanto, um conceito que resulta da interação das facetas arquetipal (símbolos primários-mitos) e sociocultural (ideogia-utopia) do imaginário bidimensional e condensa, num discurso racionalizante, mediante as metáforas e alegorias, o fluxo de imagens arquetípicas provenientes do nível fundador (o inconsciente coletivo específico com a sua pluralidade de arquétipos, as Urbilder como queria Adolf Portmann $)^{6}$. Deste modo, percebe-se melhor que o ideologe$m a$ condensa, pela via da racionalização ideo-metafórica, as imagens arquetípicas sob forma de símbolos primários (Ricoeur) e de símbolos complexos (mitos) e as figuras ideológicas, metafóricas, alegóricas e utópicas no nível racional da “[...] tópica sociocultural” (Durand, 2000, 
p. 83). Este nível corresponde às atividades racionais e lógicas mediatizadas pelas conceptualizações, codificações jurídicas ideologias, reflexões pedagógicas (no sentido também social do termo), utopias e epistemologias, etc.: "[...] neste nível, o mythos positiva-se, se assim se pode dizer, em epopeia e logiciza-se em logos" (Durand, 2000, p. 145). Assim, o ideologema aparece como uma espécie de submarino que parte do sentido histórico (literal, próprio), situado no porto racional (superego social) da tópica, em direção ao nível fundador (o designado id social ou antropológico), passando pelo nível actancial (ego social), com a tarefa de coletar os traços míticos, através dos diferentes sentidos, alegórico, metafórico e anagógico, a fim de fazer o caminho inverso. Este caminho será sempre um movimento de vaivém contínuo em direção ao nível racional, mas antes procedendo, no nível actancial (theatrum societatis com os seus atores, hierarquias, castas, estratificações), a uma espécie de trabalho de centrifugação através das metáforas e das alegorias em que o sentido verbal e epitético das imagens se substancializa, ou, como diriam Jean Duvignaud e Michel Maffesoli, se teatraliza (Durand, 2000)7. É neste sentido que podemos dizer que o símbolo se esconde por detrás da sua máscara, ou seja, teatraliza-se em forma de metáfora:

\begin{abstract}
[...] há mais na metáfora do que no símbolo, no sentido de que ela traz à linguagem a semântica implícita do símbolo, o que permanece confuso no símbolo [...] é clarificado na tensão da enunciação metafórica [...]. Mas há mais no símbolo do que na metáfora. A metáfora é o procedimento linguístico - forma bizarra de predicação - dentro do qual se deposita o poder simbólico. [...] As metáforas são precisamente a superfície linguística dos símbolos e devem o seu poder de relacionar a superfície semântica com a superfície pré-semântica nas profundidades da experiência humana (Ricoeur, 1987, p. 81).
\end{abstract}

Deste modo, não podemos deixar de assinalar que o ideologema fornece dois fundamentos à elaboração de uma espécie de atlas ideo-metafórico-mítico do imaginário educacional: um princípio de inteligibilidade ao conjunto heterogéneo de figuras que povoam o imaginário educacional, e uma hierarquia de sentidos: do histórico (literal/factual) ao simbólico, não na linha dos símbolos primários e autênticos de que fala Paul Ricoeur (1988, p. 173-181), mas na linha metafórica e alegorizante como o pretendem Daniel Hameline (1986) e Nanine Charbonnel (1991a). O ideologema parece-nos, assim, como um conceito heurístico que traz uma espécie de valor acrescentado ao estudo do imaginário educacional. Este tipo de imaginário empobrecido situa-se entre o espartilho ideológico e a os traços degradados do mito, necessitando, por isso mesmo, de um conceito que articule em si essas especificidades e que deles dê conta ainda que sob a influência de metáforas, alegorias, símbolos culturais e de outras figuras de estilo inerentes à linguagem da educação (Reboul, 1984; 1994).

A identificação do ideologema no estudo dos textos, educacionais e pedagógicos, que são a nossa fonte principal de trabalho hermenêutico, imita uma caçada na medida em que os ideologemas, à semelhança 
das presas de caça, deixam um rasto que urge seguir para não se deixar escapar o seu conteúdo que pode revelar-se uma boa surpresa mítica. Para que a caça conheça um sucesso real, o hermeneuta deve estar atento aos sinais emitidos pelos ideologemas disseminados, ou mesmo em fuga, no labirinto textual. A estes sinais, que funcionam como uma espécie de GPS, denominá-los de indicadores ideologémicos definidos como aqueles elementos semânticos expressivos saturados simultaneamente de ideologia e de ressonâncias míticas que os ideologemas emitem em contínuo. Como já se depreende, cabe aos indicadores referidos assinalarem, à semelhança dos latidos do cão do caçador quando fareja a caça por perto, a presença dos ideologemas dissimulada na floresta de frases que constitui o texto. Os indicadores ideologémicos, assim definidos, permitem-nos melhor visualizar os ideologemas acompanhados do seu cortejo de traços míticos degradados, de metáforas, de alegorias e mesmo de símbolos ainda que rarefeitos ou fortemente ideologizados, compreender a sua natureza e articulá-los, por exemplo, aos principais mitos da nossa tradição greco-romana ou a determinada tradição retórica.

Na base do ideologema construímos o décor ideologémico com o recurso a uma mitanálise que, em nome da inseparabilidade do texto do seu contexto, visa a detecção de traços míticos normalmente latentes e degradados e que torna a tarefa do hermeneuta semelhante à do explorador que procura na Amazônia uma borboleta. Neste sentido, dada à natureza ideo-metafórica do discurso filosófico, histórico, sociológico, psicológico, biológico, literário, entre outros, sobre a educação, aquilo que razoavelmente o hermeneuta pode esperar é de encontrar traços míticos dissimulados nas ideias-imagens de que falava Bronislaw Baczko (1984, p. 47): "Os princípios e os conceitos abstratos só se tornam ideias-força quando eles são capazes de se tornarem núcleos em torno dos quais se organiza a imaginação coletiva. A extensão das suas auréolas imaginárias faz com que eles ganhem redundância emocional". Para uma melhor compreensão da dificuldade da tarefa apontada, importa que o hermeneuta reflita sobre o contributo de Ricoeur que salienta o seguinte: a ideologia (imaginação reprodutora) só ganha sentido se for pensada em relação à utopia (imaginação produtora) e vice-versa e aqui nos encontramos no domínio do imaginário social onde a racionalização progressiva do mítico torna o semantismo arquetipal mais rarefeito ou liquefeito complicando imenso a interpretação: "Tudo se passa como se este imaginário repousasse sobre a tensão entre uma função de integração e uma função de subversão. [...] Tudo se passa como se o imaginário social só pudesse exercer a sua função excêntrica através da utopia e a sua função de reduplicação do real pelo canal da ideologia" (Ricoeur, 1986a, p. 384). Neste contexto, entende-se melhor a natureza do décor ideologémico ${ }^{8}$ definido por nós como uma espécie de mise en scène de ideologemas redundantes e significativos de uma dada cultura, de um dado corpus textual, de uma dada civilização que tem como objetivo a construção de uma paisagem ideo-mítica dotada de uma "pregnância simbólica" (Cassirer, 1998, p. 238) quer do ponto de vista da tradição cultural e social, quer da tradição mítica.

Educação \& Realidade, Porto Alegre, v. 43, n. 1, p. 73-95, jan./mar. 2018. 
O Imaginário Educacional na Perspetiva de Gilbert Durand

Face ao exposto, parece-nos que o modelo hermenêutico proposto por Gilbert Durand, que ele denominou de mitanálise (e que nós o usamos no seu sentido mais genérico $)^{9}$, ser aquele que melhor se adequa no plano hermenêutico para detectar, ao nível latente e ao nível patente ou manifesto, os conteúdos semânticos passíveis de revelarem algum interesse mítico. Por isso, desenvolveremos em seguida o modelo atrás referido.

\section{Gilbert Durand e a Mitanálise}

O conceito de mitanálise foi usado, pela primeira vez, por Denis de Rougemont (1961). Gilbert Durand retoma-o em 1976 no seu artigo intitulado La Cité et les Divisions du Royaume. Vers une Sociologie des Profondeurs (Durand, 1977), e usa-o novamente na sua obra Figures Mythiques et Visages de l'Oeuvre (Durand, 1979b), passando por outros estudos (Durand, 1980a; 1981; 1982; 1983b). Num dos seus últimos trabalhos, intitulado precisamente Introduction à la Mythodologie: mythes et sociétés (Durand, 2000), o conceito é amplamente desenvolvido e o seu potencial heurístico é explorado mediante os seus principais conceitos operatórios.

A mitanálise é uma hermenêutica pluridisciplinar que tem com um dos seus principais objetivos a localização, e sua consequente interpretação, das imagens, dos símbolos e dos mitos no imaginário das culturas. Ela realiza a síntese pluridisciplinar de teorias e dos métodos antropológicos, filosóficos, sociológicos, históricos, psicológicos e literários. Em última instância, a mitanálise não é uma mitodologia, como método próprio ao estudo do imaginário, que se funda na análise comparatista dos procedimentos simbólicos como elementos determinantes da criação literária e artística (mitocrítica), bem como na qualidade de elementos sintomáticos das atitudes socioculturais (mitanálise). A mitanálise faz ressaltar a importância da intertextualidade na contextualidade o que é importante porque ela, com a mitocrítica, constituem uma mitodologia entendida como uma disciplina interpretativa do comportamento mitogênico da humanidade. Porém, a passagem do texto ao contexto, isto é, a contestações de caráter mais social, em que a mitanálise tem como uma das suas missões identificar “[...] os núcleos míticos ou simplesmente simbólicos que são significativos duma sociedade num dado momento da sua formação" (Durand, 2000, p. 216-217), não se faz de modo rápido nem simples e isso devido a duas razões: a primeira obriga a que o miticiano tenha um conhecimento sólido dos mecanismos hermenêuticos, possua, no nosso caso, uma ampla e segura visão da tradição mítica ocidental sem, contudo, esquecer as tradições culturais de que essas mesmas mitologias são solidárias e, por último, que possua uma sensibilidade mítico-simbólica, em tudo semelhante à empatia (à Einfühlung) que é necessária aos psicanalistas, que Fernando Pessoa (1990) chamaria de simpatia e que Karl Kérenyi (1974) designa ouvido especial como iremos ver mais adiante; a segunda razão obriga já o seu artesão a conhecer não somente a obra de dado autor ou 
autores de dada época, bem como a conhecer a bacia semântica no qual esse ou esses autores confeccionaram os seus produtos culturais ${ }^{10}$.

Trata-se, assim, duma hermenêutica que se interessa tanto pelos mitos literários, como pelos artísticos, sociais, educacionais e políticos, mas no seu contexto histórico-social e político, seja ele micro ou macro. Deste modo, afirma-se como um modelo de análise de mitos em tensão numa certa sociedade e em dada época, mas como no interior das culturas dificilmente se encontram mitos no seu estado puro, a mitanálise tem especialmente que se ater ao estudo dos mitologemas e de traços míticos ora latentes, ora manifestos. É por isso que, do ponto de vista metodológico,

[...] toda a mitanálise deverá começar por um exame mitocrítico bastante exaustivo das 'obras' - ou dos 'bens' - de um época ou de uma dada cultura. Pinturas, esculturas, monumentos, ideologias, códigos jurídicos, rituais religiosos, costumes, vestuário e cosméticos, numa palavra todo o conteúdo do inventário antropológico é por igual convidado a informar-nos sobre tal ou tal momento da alma individual ou coletiva (Durand, 1979b, p. 306).

A mitanálise faz da narração mítica o "[...] último referencial da compreensão dos fenómenos humanos” (Durand, 1980b, p. 84), sem por isso dispensar uma sólida "epistemologia do significado" de sabor durandiano (Durand, 2000, p. 47). Este tipo de epistemologia afirma, por sua vez, o primado do significado e do seu sentido figurado, quer dizer o semantismo figurado em detrimento do "[...] não sentido do semiótico e do arbitrário do significante” (Durand, 2000, p. 81). Por último, realça a importância do mito e do símbolo (Durand, 1984; 1996; 2000). Daí que Gilbert Durand tenha definido a mitanálise como

\begin{abstract}
[...] um método de análise científica dos mitos que visa extrair não somente o sentido psicológico (Paul Diel, James Hillman, Yves Durand), mas o sentido sociológico (Cl. Lévi-Stauss, D. Zahan, G. Durand). Mitanálise que desde o início alarga o campo individual da psicanálise, na orientação da obra de Jung, ultrapassando a redução simbólica simplificadora de Freud, e repousa sobre a afirmação do 'politeísmo' (M. Weber) das pulsões da psique. A mitanálise sociológica (G. Durand) inspirando-se simultaneamente nos trabalhos do estruturalismo de Cl. Lévi-Strauss, mas igualmente [...] em todas as investigações temáticas ou nas análises semânticas de conteúdos, procura identificar os grandes mitos diretores dos momentos históricos e dos tipos de grupos e de relações sociais (Durand, 1979b, p. 313).
\end{abstract}

A mitanálise analisa, portanto, a criação artística, mítica, cultural nos diversos contextos histórico-sócio-culturais onde os vários tipos de criação referidos advêm, visto que na prática não é viável, nem credível, separar uma determinada criação particular do seu contexto sociocultural e vice-versa como, aliás, Gilbert Durand (1983b) o reconhece. Por outras palavras, o que queremos dizer é que um texto ou uma obra ar- 
O Imaginário Educacional na Perspetiva de Gilbert Durand

tística singular são sempre o resultado de um cruzamento da história, dos movimentos sociais, dos tipos psicológicos e das biografias. $\mathrm{O}$ agora afirmado significa que os domínios estudados pela mitocrítica e pela mitanálise se interceptam porquanto o texto analisado pela primeira emerge sempre num contexto que é do domínio de análise da segunda:

[...] a mitanálise pode assim proceder de dois modos: ou ela prolonga naturalmente a mitocrítica, e esta via é preferencialmente seguida pelos literários formados na análise dos textos, ou - e é a via filosófica - ela parte de sequências e de mitemas de um mito bem estabelecido para ler as ressonâncias de dada sociedade ou de dado momento histórico. Sem nunca perder de vista, todavia, que toda a sociedade é modelada por uma tópica sistémica e que a alma de um grupo (povo, etnia, nação, ou tribo...) é sempre mais ou menos 'malhada' (Durand, 2000, p. 224-225).

A mitanálise prolonga naturalmente a mitocrítica que visa a detecção de mitemas, mitologemas e de mito particularmente nos textos literários, enquanto a mitanálise estuda a atuação das correntes mitogênicas (leia-se mitos diretores) que irrigam os contextos socioculturais. Dito de outro modo, a mitanálise tenta perceber, por um lado, como é que uma dada época sociocultural, num contexto histórico-social determinado, é tributário, nas suas diversas expressões, de determinadas figuras míticas, de certos mitos diretores, ainda que degradados, e, por outro, procura igualmente perceber como é que esses mitos ou figuras míticas permanecem, derivam ou se desgastam (Durand, 1996). A mitanálise visa, portanto, a detecção dos traços míticos, temas míticos, mitos, figuras míticas latentes ou difusos (devedores dum mito implícito) e patentes (devedores dum mito explícito) por intermédio da redundância do mito (Lévi-Strauss), que é uma das suas principais características, que se repete para impregnar, para melhor, diríamos, persuadir tende a ser mais visível em contextos socioculturais através da sua produção artística e literária ( $1^{\circ}$ caso), do que no tocante à produção de tipo mais ideológico (o domínio da conceptualização: pedagogias, epistemologias, ideologias etc.) e sócio-histórico ( $2^{\circ}$ caso). No primeiro caso, as possibilidades da redundância acontecer aumentam se tratar-se duma análise que tenha por base uma escala de grande amplitude, ou seja, que se debruce sobre a obra de um autor, ou no conjunto das obras de uma época (o período renascentista, o período barroco, o período romântico etc.); ao contrário, quando se trata duma análise feita numa escala de pequena amplitude, como é o caso duma quadra, dum soneto, duma novela, dum poema ou mesmo num pequeno romance, as possibilidades de identificação do mítico ficam francamente reduzidas.

$\mathrm{O}$ agora exposto torna-se mais claro se fizermos apelo à noção de tópica sociocultural, tal como ela se apresenta explanada na obra de Gilbert Durand (2000). A respeito deste conceito, importa aqui referir que o espaço natural das produções políticas, ideológicas e científicas é o do nível racional (o superego institucional), enquanto o nível actancial (o ego societal), estando mais próximo do nivel fundador (o isso psicoide), oferece melhores condições para acolher as produções literárias e 
artísticas, visto que neste nível a força simbólica é ainda elevada, assim como o índice mítico está ainda a racionalizar-se progressivamente. $\mathrm{O}$ que pretendemos, pois dizer é que graças à tópica sociocultural (Durand, 2000, p. 151), pode-se compreender melhor os movimentos míticos quer ascensionais (racionalização progressiva do mítico: máximo de racionalidade - discursos unívocos), que circulam desde o nível fundador da tópica até ao nível racional, passando pelo nível actancial, quer descensionais (mitologização progressiva dos conteúdo ideo-racionais: máximo de não racionalidade - discursos dilemáticos), ou seja, aqueles que partem do nível racional, passando pelo nível actancial, até ao nível fundador. É pois neste movimento ora ascensional, ora descensional que o miticiano ${ }^{11}$ pode caçar, ao nível do manifesto ou do patente, a presa mítica (Gilbert Durand) ainda que, na grande maioria das vezes, metaforizada:

\begin{abstract}
Um mito desgasta-se uma vez que há deriva [...] Ele nunca desaparece porque os mitemas são em número finito [...] que se combinam segundo um outro número limitado, mas mais alargado, de mitos; quando um mito desaparece, aparece outro que o substitui. Mas eles giram em círculo porque, para dizer a verdade, não há mitos novos. Paradoxalmente, qualquer mito é sempre novo porque está investido numa cultura e numa consciência, ao contrário do seu esquematismo (Durand, 1996, p. 105).
\end{abstract}

Outro conceito complementar a este é o de bacia semântica que se inspira na metáfora potomológica (do grego potamos: rio) ou hidrográfica (a bacia fluvial), é um conceito já implícito da tópica sociocultural, e serve para explicar os percursos, as permanências e as mudanças mitogênicas em determinados momentos da vida de uma sociedade. Explica também o renascimento, a ressurgência ou emergência e adormecimento de dado mito ${ }^{12}$, mesmo sob a forma de mitologemas, no interior da memória coletiva e sociocultural de determinada sociedade constituída pelos seus modos de vida, herança cultural, língua natural, arquivos históricos, etc. Todavia, esta memória social está em constante movimento, pois recebe, em permanência, novas informações enquanto outras se perdem ou tenderão mesmo a eclipsar-se. Sofre igualmente a consequência de acontecimentos externos que a afetarão e a moldarão de modo mais ou menos perene: "[...] é assim que se passa de um trend [que significa corrente e cujo começo se faz ainda latentemente, ocultado por 'ribeiros'] hercúleo, a um outro mercuriano, depois apolínio, prometeico, dionisíaco, etc.” (Durand, 1996, p. 151). Por outras palavras, ao fim de uma geração (25 a 30 anos) ou dum período de um século, operam-se mudanças significativas, tanto quantitativas com qualitativas, motivadas pela reinjeção, que não é uma mera repetição mecânica estereotipada, de informação e de acontecimentos sociopolíticos, culturais e econômicos que marcam os estilos duma época. É pois este tipo de reinjeção, que atua no seio de um conjunto sociocultural, que Gilbert Durand denomina de bacia semântica, e que é analisado, do ponto de vista do imaginário, pelos regimes imaginários diurno e 
O Imaginário Educacional na Perspetiva de Gilbert Durand

noturno (Gilbert Durand), além dos mitos privilegiados de dada época serem igualmente considerados.

O modelo hermenêutico da mitanálise não tem a sua tarefa fácil no que concerne à detecção dos traços míticos, pois, como bem demonstrou Jean-Pirerre Sironneau (1980; 2005), a maioria das vezes, como atrás o sublinhamos, esses traços encontram-se degradados, disseminados ou traduzidos num outro tipo de discurso que, à primeira vista, não revela qualquer semelhança com qualquer estrutura mítica (Sironneau, 1993). Neste sentido, como, aliás, refere o autor, não é de esperar que ao nível do imaginário social (ideologia-utopia), histórico, político e educacional, entre outros, encontremos uma presença significativa de traços míticos ou de mitologemas (organização de elementos, motivos ou tema mitológicos) à superfície, visto tratar-se, como se pode perceber, duma espécie de imaginário que tende a ser sintemático (René Alleau), senão mesmo estereotipado. Paralelamente, entende-se que o destino do imaginário educacional não difira em muito do imaginário ideológico o que faz dele um imaginário ingrato porque exige do miticiano um cuidado hermenêutico acrescido na coleção do sentido mítico. Neste contexto, podemos afirmar que mesmo com estas limitações optamos, do ponto de vista hermenêutico e epistemológico, pela mitanálise em detrimento da mitocrítica, mesmo sabendo que o modelo mitanalítico prolonga o mitocrítico, porque ela alarga o nosso campo de atuação hermenêutico, por conseguinte, a presa mítica estará mais ao nosso alcance. Por outras palavras, a mitanálise, ao tratar da circulação dos movimentos mitogênicos no interior da tópica sociocultural na perspectiva sociológica, é inseparável de uma mitocrítica no seu sentido mais amplo, ou seja, que não restrinja a sua ação hermenêutica, como o pretendia Gilbert Durand, aos meros textos literários e poéticos, mas também aos textos políticos, artísticos, científicos, pedagógico-educacionais, etc. Além disso, como trabalhar os mitos diretores de dada sociedade, de dado período histórico (contexto) sem recorrermos às fontes produzidas ao mesmo tempo pela sua cultura (textos)?

\section{Do Interesse da Mitanálise na Hermenêutica dos Textos Educacionais}

Os contributos de Jean-Pierre Sironneau $(1980 ; 2005)$ sobre a temática da relação ideologia-mito incitam-nos a pensar que o modelo hermenêutico por ele aplicado (a mitanálise) pode igualmente ser frutuoso, do ponto de vista mítico, quando aplicado à temática educacional se atendermos: "Ainda que o imaginário ideológico seja um imaginário empobrecido, apertado num discurso pretensamente racional, filosófico ou científico, que exclui a priori as imagens poéticas e os símbolos religiosos, ele pode não obstante ser objeto de uma mitanálise" (Sironneau, 2005, p. 191). É o caso precisamente das teorias pedagógicas e educacionais que se, por um lado, se revestem de uma pretensa racionalidade (recorrendo às ciências e à sua lógica cientificizante), por outro lado, através de uma hermenêutica adequada - a mitanálise no 
seu sentido mais largo, isto é, enquanto prolongamento da mitocrítica - revelam, nos seus interstícios, traços míticos mais ou menos escondidos e que, por sua vez, reenviam para os grandes mitos da tradição cultural ocidental.

Jean-Pierre Sironneau nos seus trabalhos de sociologia política e das religiões detectou nas ideologias políticas modernas (que ele designou de religiões políticas), nomeadamente no nacional-socialismo e no socialismo e comunismo, traços de antigos mitos de origem ou de antigos mitos escatológicos. Aquilo que pretendemos dizer é que o autor percebeu bem que no caso do nacional-socialismo esta ideologia, do ponto de vista mítico, era dominada simultaneamente pela nostalgia das origens e por uma dominante escatológica complementar da nostalgia das origens na medida em que "[...] o reino milenar (o Reich de mil anos) devia ser uma restauração [através da figura messiânica - o Führer] do poder originário dos arianos" (Sironneau, 1980, p. 19) e, por consequência, essa mesma restauração criaria não só um mundo novo, mas igualmente um homem novo. No caso do socialismo e do comunismo encontrou "Uma combinação entre os sonhos escatológicos do milenarismo e os sonhos das 'Luzes'” (Sironneau, 1980 p. 20). Do ponto de vista mítico é, contudo, o cenário milenarista, ainda que traduzido em linguagem secularizada, que caracteriza ambos as ideologias políticas (Sironneau, 19890).

Face ao exposto, e se Jean-Pierre Sironneau, aplicou a mitanálise com sucesso às ideologias políticas, nós perguntamo-nos o que é que impede aos filósofos da educação de fazerem a mesma aplicação mitanalítica à razão educativa (Jolibert, 1987), ou seja, à história do pensamento educativo com o intuito de encontrar latentemente, porque ao nível manifesto ou patente é mais raro, diversos traços míticos, mesmo que degradados ou camuflados, presentes nas ideias educativas desse mesmo pensamento, bem como nos discursos pedagógicos mais diversos. Neste contexto, não é difícil, por exemplo, encontrar, particularmente ao nível latente, o mito de Prometeu ${ }^{13}$ nos textos educativos e pedagógicos dos séculos XVIII e XIX, especialmente pode detrás das ideias de Progresso e de Perfectibilidade (Taguieff, 2004; Passmore, 2004) associadas, por sua vez, às metáforas da luz e da modelagem estudadas por Nanine Charbonnel (1993; 1997). Mas se o mito de Prometeu se encontra associado à tradição educativas das Luzes, os mitos de Hermes, de Dionísio, de Frankenstein, de Fausto, entre outros exemplos possíveis, também não andam longe das tendências educativas mais contemporâneas, nomeadamente do movimento da Educação Nova, que só si mereceriam um estudo à parte ${ }^{14}$.

Também nesta perspectiva, pode igualmente ser chamada à colação os trabalhos de Olivier Reboul, Daniel Hameline, Nanine Charbonnel, Israel Scheffler, Graham Low, entre outros, que, do ponto de vista educacional, contribuíram de modo muito significativo para se compreender o estatuto que a metáfora assume no seio dos textos e das práticas discursivas da tradição educativa ocidental. É certo que mesmo sabendo que a ideologia educativa navega num imaginário empo- 
brecido, fechada numa espécie de espartilho racional e com pretensões cientificizantes, tal não impede que não seja possível através da prática mitanalítica recolher alguns traços míticos, ainda que degradados, contidos nos ditos metafóricos dos textos e discursos sobre a educação. Neste contexto, e atendendo à natureza específica da linguagem educacional, a figura do ideologema representa, na démarche mitanalítica, uma fonte heurística de especial relevância. A razão do agora afirmado deve-se ao fato de o ideologema, pela sua própria definição, estar originariamente vocacionado para melhor dar conta das alegorias, das metáforas, dos símbolos e dos mitos. Na impossibilidade de darmos exemplos de todas as figuras semânticas agora referidas, elegeremos, tão-somente, as metáforas agrícola e da luz que ilustram, a nosso ver, o modo como a mitanálise pode ser pertinente na hermenêutica dos textos educacionais.

Como sabemos, os textos que falam da educação dificilmente podem furtar aos olhares atentos da metáfora e do símbolo, por exemplo, porque aquilo que de mais dramático pode acontecer, segundo Olivier Reboul, é assistir-se a "[...] uma educação sem símbolos face a símbolos sem educação" (Reboul, 1992, p. 217-219). É precisamente para contrariar a possibilidade de uma educação sem símbolos e metáforas ou, no limite, uma educação habitada por símbolos e metáforas mortas que escolhemos os exemplos das metáforas citadas anteriormente para ilustrar, por um lado, que a modernidade educativa, especialmente o movimento da Educação Nova, não se pode pensar nem escrever sem o recurso semântico e mesmo hermenêutico da metáfora agrícola e que, por outro lado, as metáforas, na sua qualidade de janelas abertas aos símbolos, tendem, não assim tão poucas vezes, a aproximarem-nos dos mitos da nossa tradição ocidental sem que muitas vezes disso nos apercebamos.

No caso específico das metáforas sejam elas hortícolas ${ }^{15}$ (que subsumem o crescimento ou a cultura vegetal), de alimentação, de navegação, da luz e das trevas, de modelagem, de deslocação, da viagem (que implica o percurso-deslocação), do retraimento, do transbordamento, da modelagem, do enchimento-alimentação, entre outras ${ }^{16}$, contêm em si raízes simbólicas que são autênticos depósitos de germes míticos. Como nos ensinou Paul Ricoeur, entendemos que o poder metafórico, à semelhança de um riacho, não só vai desaguar a um rio subterrâneo designado de símbolo como é também dele sintoma. Daniel Hameline, quanto a nós, esqueceu que há mais no símbolo do que na metáfora porque o símbolo transporta em si um excesso de se significação que convoca naturalmente uma semântica profunda: a onírica, a poética e a cósmica (Ricoeur, 1988, p. 173-181). Mas se há mais no símbolo do que na metáfora, enquanto comparação que "[...] oferece as suas razões e se mostra desse modo razoável” (Hameline, 1986, p. 139), podemos, por conseguinte, afirmar, com Daniel Hameline, que do lado da metáfora

Aceita-se que um aluno não é nem uma planta, nem um frasco, nem uma plasticina, nem um explorador, nem um arquiteto, nem um pássaro-raptor, nem um carro de cor- 
rida, nem um guaxinim. Mas compará-lo a uma planta, a um frasco, a uma plasticina, etc., e mesmo a um guaxinim permite dizer qualquer coisa que se pode controlar e que não é uma simples brincadeira nem um mero efeito de estilo (Hameline, 1986, p. 139).

E do lado do símbolo podemos dizer, na companhia de Paul Ricoeur, que é pela metáfora viva que acedemos à semântica do símbolo e é desta semântica que a imaginação viva e se alimenta. Se da metáfora importa reter que ela ocorre "[...] no universo já purificado do logos" (Ricoeur, 1987, p. 71) e que tem o poder de relacionar a superfície semântica com a superfície pré-semântica do símbolo, já do símbolo aquilo que importa reter é que ele "[...] hesita na linha divisória entre o bios e o logos”, ou seja, “[...] mergulham as suas raízes nas constelações duradoiras da vida do sentimento e do universo" (Ricoeur, 1987, p. 71, p. 76):

Há mais na metáfora do que no símbolo, no sentido de que ela traz à linguagem a semântica implícita do símbolo [...]. Mas há mais no símbolo do que na metáfora. A metáfora é o procedimento linguístico - forma bizarra de predicação - dentro do qual se deposita o poder simbólico. [...] As metáforas são precisamente a superfície linguística dos símbolos e devem o seu poder de relacionar a superfície semântica com a superfície pré-semântica nas profundidades da experiência humana (Ricoeur, 1987, p. 80-81).

A metáfora agrícola, aliás, muito presente nos textos consagrados às novas ideias educativas exprime sinteticamente a relação simbiótica e simbólica entre a educação da criança e o crescimento ou cultura vegetal. Este tipo de metáfora visa comparar, ainda que o grau comparativo varie na sua forma e na sua substância, o ciclo educacional-cultural da criança com o ciclo naturalista da planta. Nesta linha percebe-se que a pedagogia faça da metáfora hortícola uma espécie de verdade elementar, algo que va de soi, ou seja, que se impõe naturalmente aos olhos daqueles que escrevem ou que falam sobre a coisa educativa:

A educação é efetivamente uma cultura da criança que, à semelhança de outros seres vivos, vegetais ou animais, traz em si-mesmo as fontes e os mecanismos motores do seu crescimento e das aquisições. A metáfora hortícola é uma constante de todas as correntes pedagógicas que opuseram o lugar-comum do vivente a fazer (ou deixar) crescer, ao lugar-comum do produto (mecânico, mas mais frequentemente social) à modelagem (Hameline, 1986, p. 182).

Nós sabemos que a metáfora hortícola regressou, quase como uma obsessão, no início do século XX, junto daqueles que preconizam a educação nova. [...] A metáfora é assim proposta para celebrar o milagre da infância, desde logo que este se desenrola naturalmente. Encarregam-na de 'dar a ver' o pequeno ser que se desenvolve por si-próprio, segundo um plano que ele traz consigo e que não lhe poderia ser ditado do exterior, à semelhança da planta em torno da qual o bom jardineiro pedagogo se contenta pre- 
O Imaginário Educacional na Perspetiva de Gilbert Durand

parar e cuidar o terreno. Mas a metáfora hortícola da educação só pode exprimir o romantismo da não-intervenção fazendo abstração, na imagerie [no original], da realidade da horticultura científica, brevemente industrial (Hameline, 2000, p. 49).

Os autores da Educação Nova usam a metáfora agrícola nos seus textos como emblema da espontaneidade para melhor insistirem que se deve respeitar o crescimento natural da criança tal como o jardineiro o faz relativamente às plantas que ele cuida: “[...] a metáfora do jardineiro erigida em paradigma torna-se o instrumento que permite ver e compreender, numa primeira aproximação, que tem possibilidades, pela intuição do semelhante, de dizer de imediato o essencial" (Hameline, 1986, p. 180-183). Neste contexto, não deixa de ser estimulante, senão mesmo pertinente, interrogarmo-nos à luz da hermenêutica mitanalítica, até que ponto a metáfora agrícola não nos conduz, por um lado, a toda a riqueza do simbolismo vegetal tão bem estudado por Mircea Eliade (2004), e que, por outro lado, se por intermédio desse mesmo simbolismo não encontraremos nós os deuses e as deusas da vegetação (Dionísio, Deméter, Ártemis) a espreitar por detrás das ideias educativas e pedagógicas aparentemente racionais e insuspeitas de acolher no seu seio traços míticos aparentemente obscuros.

Aliás, a mesma interrogação pode ser feita, por exemplo, relativamente à metáfora da luz igualmente presente nos textos e discursos sobre a educação, como, aliás, bem o mostra Nanine Charbonnel (1997) Esta metáfora, associada à das trevas, parece estruturar a narrativa ideo-pedagógica e educacional do ideário educativo iluminista e positivista e o seu prolongamento e influência na ideia de progresso, na sua feição educativa (Hameline, 2000), que os discursos e os textos pedagógicos e educacionais de hoje ainda refletem:

O schème [no texto] da luz, tal como ele é recebido no dito progressista da educação durante o século XIX, é inicialmente o Fiat lux do Génesis laicizado para celebrar os benefícios da instrução pública. O Progresso, - proclamado até à exaustão -, resultará de uma feliz conjugação da instrução com as forças motrizes. A primeira e as segundas têm em comum produzir a energia donde a luz pode brotar, nas fábricas e nos espíritos, nas cabanas e nos corações (Hameline, 1986, p. 160) ${ }^{17}$.

E é assim numa acepção laica, doravante tradicional, da metáfora da luz que nós somos convidados a celebrar o progresso, na mesma cidade de Calvino cuja divisa é a de Post tenebras lux (Hameline, 2000, p. 25)

Do ponto de vista mítico, e de forma sintética, Gilbert Durand coloca a luz no seu regime diurno tipificado pelas estruturas heroicas e representados pelos deuses e heróis solares (Zeus, Apolo, Prometeu, Teseu, Hércules), enquanto as trevas aparecem do lado do regime noturno tipificado pelas estruturas sintéticas e místicas cujos deuses, que encarnam as trevas, são Hades e Dionísio. Do ponto de vista simbólico podemos dizer que sob o signo da luz conjugam-se, entre outros, o sím- 
bolo da arma heroica, a simbólica do sol, do ar, do batismo enquanto do lado das trevas aparece a simbólica da noite, da lua, da caverna, do ventre, entre outros (Durand, 1984b).

Outra ilustração possível da pertinência da mitanálise no quadro da hermenêutica dos textos educacionais surge-nos do lado de Olivier Reboul (1992) que, na sua obra intitulada Le Valeurs de l'Éducation, desenvolve, no capítulo 9, o seguinte tema: O símbolo, linguagem dos valores. No capítulo agora referido pensamos que o autor aplica, ainda que de uma forma genérica, a mitanálise só que em vez de estar direcionada para os mitos, Oliver Reboul aplica-a aos símbolos. Porém, aquilo que importa reter é a dimensão heurística da sua leitura hermenêutica, que em muito tem a ver com os procedimentos da mitocrítica e da própria mitanálise enquanto seu prolongamento, que sublinha a importância do símbolo na Filosofia da Educação e, muito particularmente, no campo da Axiologia Educacional e cuja tese pode assim ser resumida:

Todo o símbolo simboliza o valor. Todo o símbolo participa naquilo que ele simboliza e, desse modo, pode ser profanado. Estes conceitos de participação e de profanação não nos colocam eles em presença do sagrado? Eu penso o que simboliza um símbolo, é sempre, de alguma maneira, o sagrado (Reboul, 1992, p. 2012).

No capítulo mencionado, o autor oferece, num primeiro momento, exemplos de símbolos simples, complexo e de interpretação simbólica (Reboul, 1992); num segundo momento interroga-se sobre o que é um símbolo (ele faz ver, reúne, faz agir, faz sentir, dá que pensar e, por fim, o que diz o símbolo) e diz que ele é um grande meio de ensino (Reboul, 1992); num terceiro momento debruça-se sobre os símbolos complexos (o símbolo e a alegoria e dá um exemplo) (Reboul, 1992), no quarto momento, e último, Olivier Reboul se interroga se pode escapar aos símbolos (nem racional, nem eficaz, a gentileza, a honra como exemplos). É, por conseguinte, neste momento que ele reflete sobre a importância do símbolo como algo que dá que pensar (instrução, integração, argumentação, reflexão), salientando que é preciso passar dos valores sociais (sempre particulares e culturais) aos valores propriamente humanos que são sempre universais e esta passagem é feita graças ao símbolo que ele designa de "válido" (Reboul, 1992, p. 208).

Por fim, e já anteriormente afloramos esta questão, termina com a seguinte afirmação: "Uma educação sem símbolos face a símbolos sem educação" (Reboul, 1992, p. 217-219). Neste contexto, não resistimos a salientar, na linha de Olivier Reboul, que a nossa cultura, a nossa educação em especial, necessita urgentemente, por um lado, de encontrar (de nomear diríamos) não só os seus símbolos válidos (Paul Ricoeur diria verdadeiros), como também as suas alegorias, metáforas e mitos, mas por outro precisa também de educar os seus símbolos, as suas alegorias, metáforas e mitos e educar aqui confunde-se com a definição que o próprio Olivier Reboul dá de símbolo válido, além de pensarmos que a mitanálise no seu sentido mais lato parecer adequar-se a esta tarefa: 
O Imaginário Educacional na Perspetiva de Gilbert Durand

Eu penso: que é aquele que pode fazer objeto de uma reflexão universal, aquele que conserva a sua força emotiva depois de ter sido submetido à prova da crítica, aquele que se pode compreender, admirar, amar além da cultura donde ele emana. A interpretação da Natividade por Alain, que não era cristão, consiste precisamente a retirar uma mensagem universal. Ela é um grande exemplo daquilo que pode ser uma educação pelo símbolo: passar dos valores sociais aos valores humanos (Reboul, 1992, p. 217).

Do exposto, podemos afirmar que da exposição aos símbolos e aos mitos o horizonte existencial do intérprete ficará certamente mais enriquecido, pois o sentido tecido entre a dialética da arqueologia (virada para “[...] ressurgência de significações arcaicas pertencendo à infância da humanidade e do indivíduo" Ricoeur (1995, p. 518) e da teleologia (virada para "[...] a emergência de figuras antecipadoras da nossa aventura espiritual” Ricoeur (1995, p. 518) contribui para que a sua existência se assuma como uma promessa de uma busca do tempo perdido (lembrando a obra capital de Marcel Proust) e de uma recusa face à tortura de um tempo torturador e triturador da esperança do humano: os “[...] símbolos autênticos são verdadeiramente regressivos-progressivos; pela reminiscência, a antecipação; pelo arcaísmo, a profecia” (Ricoeur, 1995, p. 519). Por último, a mitanálise, na sua acepção mais ampla, representa um contributo, entre outros possíveis, para estimular um "conflito de interpretações" (Paul Ricoeur) que é, a nosso ver, uma das condições para que a hermenêutica educacional não se esgote em meros exercícios racionais desprovidos do semantismo poderoso veiculado pelas "vidas das imagens" para evocar aqui um dos títulos de Jean-Jacques Wunenburger (2002).

Recebido em 28 de março de 2016 Aprovado em 05 de junho de 2017

\section{Notas}

1 Neil Postman usa o conceito de deus como sinónimo de grande narrativa: "Um deus, no sentido que uso a palavra, é o nome de uma grande narrativa, uma narrativa que possui credibilidade, complexidade e poder simbólico suficientes para permitir que o indivíduo organize a vida em função dela”. Usa o termo deus no sentido que Koestler o utilizou na sua obra O Deus que Falhou (1949): "uma narrativa abrangente sobre o próprio mundo, sobre as razões pelas quais as coisas são como são e sobre aquilo que podemos esperar do futuro" (Postman, 2002, p. 20).

2 Trata-se de uma figura dotada de uma forte capacidade heurística forjada por nós sobre o conceito de mitologema de Gilbert Durand e que, consequentemente, nada tem a ver, como alguns apressadamente o julgaram, com a noção de ideologema de Mikhail Bakthin e de Julia Kristeva. Para mis detalhes, consulte-se o verbete Ideologema de Carlos Ceia (2017) no seu E Dicionário de Termos Literários.

3 Veja-se o exemplo das metáforas hortícolas (crescimento ou cultura vegetal), de navegação, da modelagem, da luz, do percurso-deslocação e do enchimento-alimentação. A este respeito, consulte-se Daniel Hameline (1981) e Nanine Charbonnel (1997).

90 Educação \& Realidade, Porto Alegre, v. 43, n. 1, p. 73-95, jan./mar. 2018. 
4 Cf. Paul Ricoeur (1987, p. 57-81). É um capítulo importante que trata da relação entre metáfora e símbolo.

5 O autor define este conceito crucial da sua obra como "[...] a incessante troca que existe ao nível do imaginário entre as pulsões subjetivas e assimiladoras e as intimações objetivas emanando do meio cósmico e social" (Durand, 1984, p. 38). Mais adiante diz que o imaginário “[...] não é mais do que este trajeto no qual a representação do objeto se deixa assimilar e modelar pelos imperativos pulsionais do sujeito, e no qual reciprocamente, como magistralmente mostrou Piaget, as representações subjetivas explicam-se 'pelas acomodações anteriores do sujeito' ao meio objetivo” (Durand, 1984, p. 38).

6 Cf. Araújo e Silva (2003, p. 353-360).

7 Veja-se Gilbert Durand (1994, p. 63), onde se lê : "Constata-se que se parte de uma extremidade cheia de riachos de imagens do 'isso': é a amostra confusa de um imaginário que paulatinamente se regulariza com os diversos papéis na sua parte mediana para terminar muito empobrecido na sua extremidade superior, onde o alógico do mito tende a esbater-se em proveito da lógica corrente. É portanto num percurso temporal que os conteúdos imaginários (sonhos, desejos, mitos, etc.) de uma sociedade nascente num riacho confuso, mas importante, se consolidam, 'teatralizando-se' (Jean Duvignaud, Michel Maffesoli) nos empregos 'actanciais' (Algridas Freimas, Yves Durand), positivos ou negativos, que recebem as suas estruturas e o seu valor de 'confluências' sociais diversas (apoios políticos, económicos, militares, etc.), para finalmente racionalizar-se. Perdendo logo a sua espontaneidade mitogénica nos edifícios filosóficos, das ideologias e das codificações"

8 Forjamos este conceito inspirados na noção de décor mítico de Gilbert Durand que aparece na sua obra intitulada Le décor mythique de la Chartreuse de Parme. Les structures figuratives du roman stendhalien (Durand, 1983a): o autor salienta que este décor visa dar uma expressão privilegiada à imaginação romanesca a fim que o romance adquira o seu sentido mítico, diríamos mesmo o seu enredo mítico: "Aquilo que procura o grande romancista, é através da espessura semiológica e banal da linguagem, é tocar no íntimo do leitor os seus principais núcleos arquetipais que estruturam em segredo os desejos, o devaneio e as suas preocupações mais profundas. O décor é, portanto, tanto quanto ele o pode, subjectivo, mas de uma subjectividade universal, transcendental, quer dizer que faz apelo ao fundo imemorial dos grandes arquétipos que povoam a imaginação de toda a espécie humana. [...] Todo o romancista está submetido, pela sua vocação literária, à 'estética do espelho', mas nada impede este espelho de ser, no melhor dos casos, o espelho da alma" (Durand, 1983a, p. 13-14). Podemos salientar, como tentativa de definição, que o décor mítico é o meio pelo qual toda "[...] a literatura toca e comunga com aquilo que é simultaneamente o mais íntimo e o mais universal” (1983a, p. 14).

9 Ainda que a mitanálise tenha sido forjada para o sociólogo, tal não impede que esta noção heurística não possa ser usada no domínio das Ciências da Educação. Os conteúdos míticos identificados são passíveis de uma análise hermenêutica (o domínio da mitocrítica), mas também de uma análise sócio-histórica (domínio específico da mitanálise). Do ponto de vista metodológico, a mitanálise prolonga as orientações metodológicas da mitocrítica naquilo que diz respeito às práticas sociais, às instituições, aos documentos históricos, mesmo ao património artístico e arquitetónico. Todavia, e como Durand sempre alertou, a tarefa de identificar e de estudar as dominantes míticas na diversidade das 
formas da vida social, de um grupo, de toda uma sociedade ou mesmo duma época torna-se, a maioria das vezes, complexa e arriscada. Assim, o sociólogo das profundidades não tem a sua tarefa facilitada não só porque as dominantes míticas não se assemelham a uma espécie de flores que estão num campo ao alcance de serem colhidas, mas antes se assemelham ao seu pólen. Daí a dificuldade acrescida com a qual se depara o miticiano que tem na metodologia de Gilbert Durand uma ferramenta incontornável (Durand, 2000). A razão desta afirmação reside que aí o autor explica que a partir da construção de um mito ideal dominante é possível estudar as flutuações desse mito através das sequências cronológicas até ao seu esgotamento final, e, paralelamente, ver como esse mito dominante, atualizado em ideologias e instituições, suscita um contra-mito cujas manifestações são menos manifestas ou patentes.

10 Veja-se, por exemplo, o estudo de Cambronne (1982), que parte de uma mitocrítica das Confissões de Santo Agostinho para terminar num estudo mitanalítico onde explica como é que a corrente augustiniana irrigou uma grande parte do cristianismo ocidental.

11 Constata-se na prática hermenêutica que nem sempre é possível delimitar, mediante os conceitos auxiliares do miticiano, os elementos míticos em contextos socioculturais pelo facto desses mesmos elementos se encontrarem desfigurados, estilhaçados no interior das ideologias que modelam ou enformam esses contextos.

12 Sobre este tema, veja-se Gilbert Durand (1996, p. 81-107).

13 Jean-Pierre Sironneau (1980, p. 21) sobre este mito diz o seguinte: “A figura moderna de Prometeu cristaliza os sonhos das 'Luzes'. Esta figura torna-se mais clara com Goethe. No Prometeu de Goethe, Prometeu deixa de ser uma divindade primordial para ser o homem concebido como o génio criador de si-mesmo, que não tem mais necessidade dos deuses e assume ele próprio o seu destino. As encarnações prometeicas são muito numerosas nos séculos XVIII e XIX, no teatro e na literatura [e nós acrescentaríamos, na educação]".

14 Esta temática merecia um estudo panorâmico e aprofundado da presença destes mitos, e de outros, na tradição educativa ocidental, ainda que haja alguns estudos avulsos, nomeadamente da nossa autoria.

15 Sobre a metáfora hortícola, veja-se a fina observação de Daniel Hameline (2000, p. 49-50).

16 Nanine Charbonnel chama a atenção para o seguinte leque de metáforas no discurso educativo: "Escultura e olaria, alimentação e enchimento, jardinagem, agricultura, domesticação, artesanatos diversos, marcha e navegação" (Charbonnel, 1983, p. 157). Sobre as metáforas do enchimento, da alimentação e da modelação, consulte-se Nanine Charbonnel (1991b e 1993). A este respeito, consulte-se Israel Scheffler (2003).

17 A noção de schème, que é um conceito fundamental na obra de Gilbert Durand, aqui aparece como sinónimo de arquétipo substantivo. Para um maior desenvolvimento da noção, veja-se a sua obra Les Structures Anthropologiques de L'Imaginaire (1984b, p. 61).

18 Cf. Nanine Charbonnel (1997). 


\section{Referências}

ARAÚJO, Alberto Filipe; SILVA, Armando Malheiro da. Mitanálise: uma mitodologia do imaginário? In: ARAÚJO, Alberto Filipe; BAPTISTA, Fernando Paulo (Coord.). Variações Sobre o Imaginário: domínios, teorizações, práticas hermenêuticas. Lisboa: Instituto Piaget, 2003. P. 339-364.

BACZKO, Bronislaw. Les Imaginaires Sociaux. Mémoires et Espoirs. Paris: Payot, 1984

CAMBRONNE, Patrice. Recherches sur les Structures de l'Imaginaire dans les Confessions de Saint Augustin. Paris: Études Augustiniennes, 1982.

CASSIRER, Ernst. Filosofia de las Formas Simbólicas. III: fenomenología del reconocimiento. $2^{\text {a }}$ ed. Trad. Armando Morones. México: Fondo de Cultura Económica (FCE), 1998.

CEIA, Carlos. 'Ideologema'. In: CEIA, Carlos (Coord.). E-Dicionário de Termos Literários. Lisboa: EDTL, 2017. Disponível em: <http://www.edtl.com.pt $\geq$. Acesso em: 21 maio 2017.

CHARBONNEL, Nanine. Apport des herméneutiques du texte à l'étude du discours sur l'éducation: la place de la métaphore. In: Sciences Anthropo-Sociales. Sciences de l'Éducation. Actes - Colloque National (Paris - INA - 16/18 Septembre). Paris: Association des Enseignants et Chercheurs en Sciences de l'Éducation, 1983. P. 156-159.

CHARBONNEL, Nanine. La Tâche Aveugle: volume I: les aventures de la métaphore. Strasbourg: Presses Universitaires de Strasbourg, 1991a.

CHARBONNEL, Nanine. La Tâche Aveugle: volume II: l'important c'est d'etre propre. Strasbourg: Presses Universitaires de Strasbourg, 1991b.

CHARBONNEL, Nanine. La Tâche Aveugle: volume III: philosophie du modèle. Strasbourg: Presses Universitaires de Strasbourg, 1993.

CHARBONNEL, Nanine. La Métaphore de la Lumière dans le Discours sur l'Éducation. Revista Portuguesa de Educação, Braga, v. 10, n. 2, P. 59-70, 1997.

DURAND, Gilbert. La Cité et les Divisions du Royaume: vers une sociologie des profondeurs. Eranos-Jahrbuch, Zürich, v. 45, P. 165-219, 1977.

DURAND, Gilbert. A Imaginação Simbólica. Tradução: Maria de Fátima Morna. Lisboa: Arcádia, 1979a.

DURAND, Gilbert. Figures Mythiques et Visages de L'œuvre. Paris: Berg International, 1979b.

DURAND, Gilbert. L'Âme Tigrée: les pluriels de psyché. Paris: Denoël; Gonthier, 1980a.

DURAND, Gilbert. Science de l'Homme et Tradition. Le Nouvel Esprit Anthropologique. Paris: Berg International, 1980b.

DURAND, Gilbert. Le Social et le Mythique: pour une topique sociologique. Cahiers Internationaux de Sociologie, Paris, v. 71, P. 289-307, 1981.

DURAND, Gilbert. Mito, Símbolo e Mitodologia. Tradução: Hélder Godinho e Vitor Jabouille. Lisboa: Presença, 1982.

DURAND, Gilbert. Le Décor Mythique de la Chartreuse de Parme: les structures figuratives du roman stendhalien. 2. ed. Paris: Librairie José Corti, 1983a.

DURAND, Gilbert. Mito e Sociedade. A Mitanálise e a Sociologia das Profundezas. Tradução: Nuno Júdice. Lisboa: A Regra do Jogo, 1983b.

Educação \& Realidade, Porto Alegre, v. 43, n. 1, p. 73-95, jan./mar. 2018. 
O Imaginário Educacional na Perspetiva de Gilbert Durand

DURAND, Gilbert. La Foi du Cordonnier. Paris: Denoël, 1984a.

DURAND, Gilbert. Les Structures Anthropologiques de l'Imaginaire. 10. ed. Paris: Dunod, 1984b.

DURAND, Gilbert. L'Imaginaire: essai sur les sciences et la philosophie de l'image. Paris: Hatier, 1994.

DURAND, Gilbert. Champs de l'Imaginaire: textes réunis para Danièle Chauvin. Grenoble: Ellug, 1996.

DURAND, Gilbert. Introduction à la Mythodologie: mythes et sociétés. Paris: Albin Michel, 2000.

ELIADE, Mircea. Tratado de História das Religiões. Tradução: F. Tomaz e Natália Nunes. 4. ed. Porto: ASA, 2004.

HAMELINE, Daniel. Place et Fonction de la Métaphore dans la Pensée sur l'Éducation ou Éloge de la Rhétorique. Éducation et Recherche, Nantes, n. 3, P. 121-132, 1981

HAMELINE, Daniel. L'Éducation, ses Images et son Propos. Paris: ESF, 1986.

HAMELINE, Daniel. Qu'est-ce qu'une Idée Pédagogique? In: HANNOUN, Hubert; DROUIN-HANS, Anne-Marie (Dir.). Pour une Philosophie de l'Éducation. Dijon: Cndp/CRDP de Bourgogne, 1994. P. 149-164.

HAMELINE, Daniel. Courants et Contre-Courants dans la Pédagogie Contemporaine. Paris: ESF Éd, 2000.

JOLIBERT, Bernard. Raison et Éducation. Paris: Éditions Klincksieck, 1987.

JUNG, Carl-Gustav. Types Psychologiques. Tradução: Yves le Lay. Paris; Genève: Georg Éditeur, 1991.

KERÉNYI, Karl. De l'Origine et du Fondement de la Mythologie. In: JUNG, Carl Gustav; KERÉNYI, Charles. Introduction à l'Essence de la Mythologie. Tradução: H. E. Del Medico. Paris: Payot, 1974. P. 11-41.

LOW, Graham. Metaphor and Education. In: GIBBS JUNIOR, Raymond (Ed.). The Cambridge Handbook of Metaphor and Thought. Cambridge: Cambridge University Press, 2010. P. 212-231.

PASSMORE, John. A Perfectibilidade do Homem. Tradução: Jesualdo Correia. Rio de Janeiro: Topbooks, 2004.

PESSOA, Fernando. Mensagem e Outros Poemas Afins. Mem Martins: Europa América, 1990.

POSTMAN, Neil. O Fim da Educação: redefinindo o valor da escola. Tradução: Cassilda Alcobia. Lisboa: Relógio de Água, 2002.

PROUST, Marcel. À la recherche du temps perdu. Volumes I a IV. Paris: Éditions Gallimard, 1982-1989.

REBOUL, Olivier. Le Langage de l'Éducation. Paris: PUF, 1984

REBOUL, Olivier. L’Allégorie est-elle Pédagogique? In: REBOUL, Olivier; GARCIA, Jean-François (Dir.). Rhétorique et Pédagogie. Strasbourg: PUS, 1991. P. 9-25.

REBOUL, Olivier. Les Valeurs de l'Éducation. Paris: PUF, 1992.

REBOUL, Olivier. Introduction à la Rhétorique: théorie et pratique. 2. ed. Paris: PUF, 1994

RICOEUR, Paul. Le conflit des interprétations. Essais d'herméneutique. Paris: Du Seuil, 1969.

94 Educação \& Realidade, Porto Alegre, v. 43, n. 1, p. 73-95, jan./mar. 2018 
RICOEUR, Paul. Do Texto à Acção: ensaios de hermenêutica II. Tradução: Alcino Cartaxo. Porto: Rés, 1986a.

RICOEUR, Paul. Du Texte à l'Action: essais d'herméneutique, II. Paris: Du Seuil, $1986 \mathrm{~b}$.

RICOEUR, Paul. Teoria da Interpretação. Tradução: Artur Morão. Porto: Porto Editora, 1987.

RICOEUR, Paul. Philosophie de la Volonté: II, finitude et culpabilité. Paris: Aubier, 1988.

RICOEUR, Paul. De l'interprétation. Essai sur Freud. Paris: Du Seuil, 1995.

ROUGEMONT, Denis. Comme Toi-Même: essais sur les mythes de l'amour. Paris: Albin Michel, 1961.

SCHEFFLER, Israel. Le Langage de l'Éducation. Tradução: Michel Le Du. Paris: Klincksieck, 2003.

SIRONNEAU, Jean-Pierre. Figures de l'Imaginaire Religieux et Dérive Idéologique. Paris: L'Harmattan, 1993.

SIRONNEAU, Jean-Pierre. Idéologie et Mythe. In: CHAUVIN, Danièle; SIGANOS, André; WALTER, Philippe (Dir.). Questions de Mythocritique: dictionnaire. Paris: Imago, 2005. P. 190-191.

SIRONNEAU, Jean-Pierre. Retour du Mythe et Imaginaire Socio-Politique. In: VIERNE, Simone (Dir.). Le Retour du Mythe. Grenoble: PUG, 1980. P. 9-28.

TAGUIEFF, Pierre-André. Le Sens du Progrès: une approche historique et philosophique. Paris: Flammarion, 2004.

VIERNE, Simone. Mythocritique et Mythanalyse. Iris, Grenoble, n. 13, P. 45-56, 1993.

WUNENBURGER, Jean-Jacques. La Vie des Images. Grenoble: PUG, 2002.

Alberto Filipe Araújo é professor Catedrático do Instituto de Educação da Universidade do Minho (Braga, Portugal) e membro do Centro de Investigação em Educação (CIEd) do mesmo instituto. Os seus domínios de interesse científico são os seguintes: filosofia da educação, estudos do imaginário e história das ideias educativas. Nos últimos anos tem trabalhado especialmente sobre a relação da metáfora, do símbolo, do mito, da imaginação e do imaginário com a educação.

E-mail: afaraujo@ie.uminho.pt

Fernando José Azevedo é professor Associado com Agregação do Instituto de Educação da Universidade do Minho (Braga, Portugal), onde é o responsável pela regência de unidades curriculares de pós-graduação nas áreas da Literatura Infantil e Juvenil, Didática e Formação de Leitores. Tem larga experiência de supervisão de pesquisas de doutoramento em Literatura para a Infância. É Doutor em Ciências da Literatura e membro do Centro de Investigação em Estudos da Criança (CIEC), sendo o responsável pela linha de pesquisa Produções Culturais para as Crianças.

E-mail: fraga@ie.uminho.pt 